\title{
An Unusual Small Bowel Lesion
}

\author{
Maria Pia Costa-Santos ${ }^{a}$ João Moreira-Pinto ${ }^{b}$ Maria Helena Oliveira ${ }^{c}$ \\ Alexandre Oliveira Ferreira ${ }^{a}$ \\ ${ }^{a}$ Gastroenterology Department, Hospital Beatriz Ângelo, Loures, Portugal; ${ }^{b}$ Oncology Department, \\ Hospital Beatriz Ângelo, Loures, Portugal; ' Pathology Department, Hospital Beatriz Ângelo, Loures, Portugal
}

\section{Keywords \\ Leiomyosarcoma $\cdot$ Small bowel $\cdot$ Upper gastrointestinal bleeding}

\section{Lesão atípica do intestino delgado}

\section{Palavras-Chave}

Leiomiossarcoma $\cdot$ Intestino delgado $\cdot$ Hemorragia

digestiva alta

\section{Case Report}

A 58-year-old black female, born in Angola and living in Portugal, presented with melena, occasional vomiting, and asthenia for 1 month. She also complained of anorexia and weight loss (40 $\mathrm{kg} / 88 \mathrm{lb}$ ) in the past 2 years and reported a 7 -year history of a right thigh mass that had progressively increased in size, with an inconclusive biopsy performed in Angola. Her laboratory tests revealed iron deficiency anemia (hemoglobin $4.4 \mathrm{~g} / \mathrm{dL}$ ). Computed tomography (CT) showed a large solid lesion in the right thigh (Fig. 1a), multiple smaller lesions in the thyroid, lungs, pancreas, adrenal gland, uterus, and soft tissues, focal thickness of the small bowel wall and colon, as well as jejunal intussusception, distal to the angle of Treitz (Fig. 1b, c). Upper gastrointestinal endoscopy revealed

\section{KARGER}

karger@karger.com www.karger.com/pjg
(C) 2020 Sociedade Portuguesa de Gastrenterologia Published by S. Karger AG, Basel

Karger

Upen access

This article is licensed under the Creative Commons AttributionNonCommercial-NoDerivatives 4.0 International License (CC BY NC-ND) (http://www.karger.com/Services/OpenAccessLicense) Usage and distribution for commercial purposes as well as any distribution of modified material requires written permission. multiple ulcerative mucosal lesions with elevated edges throughout the second and third portions of the duodenum, with 10-20 $\mathrm{mm}$, without hemorrhagic stigmata and surrounded by normal mucosa (Fig. 2). The duodenal and thigh lesions were biopsied, and histology showed irregularly intersecting fascicles of spindled cells with indistinct cytoplasmic contour and a cigar-shaped nucleus and areas of necrosis. Immunohistochemically, the tumor cells were positive for $a$-smooth muscle actin, desmin, and hcaldesmon, and negative for CD117, CK AE1/AE3, and S-100 protein. Therefore, a stage IV leiomyosarcoma was diagnosed. Due to persistent melena, endoscopy was repeated and showed an ulcerative lesion in the duodenum with active oozing. Hemostasis was achieved after adrenaline injection and coagulation with argon plasma. Nausea and vomiting relieved with conservative measures and jejunal intussusception reduced spontaneously. The patient started chemotherapy with doxorubicin. However, there was disease progression and she died 8 months after the diagnosis.

\section{Discussion}

Leiomyosarcoma is a rare smooth muscle malignant neoplasm that accounts for 10-20\% of all soft tissue sarcomas [1]. It appears most commonly in the retroperitoneum, large blood vessels, and uterus, and less frequently in the lower extremities [1,2]. Both primary and metastatic leiomyosarcoma of the small bowel are extremely rare [3]. In our case, the primary tumor is unknown since the diagnosis was made at a late stage of the disease, although clin- 
Fig. 1. Computed tomography showing a large solid lesion in the right thigh consistent with leiomyosarcoma (a) and jejunal intussusception $(\mathbf{b}, \mathbf{c})$, distal to the angle of Treitz.
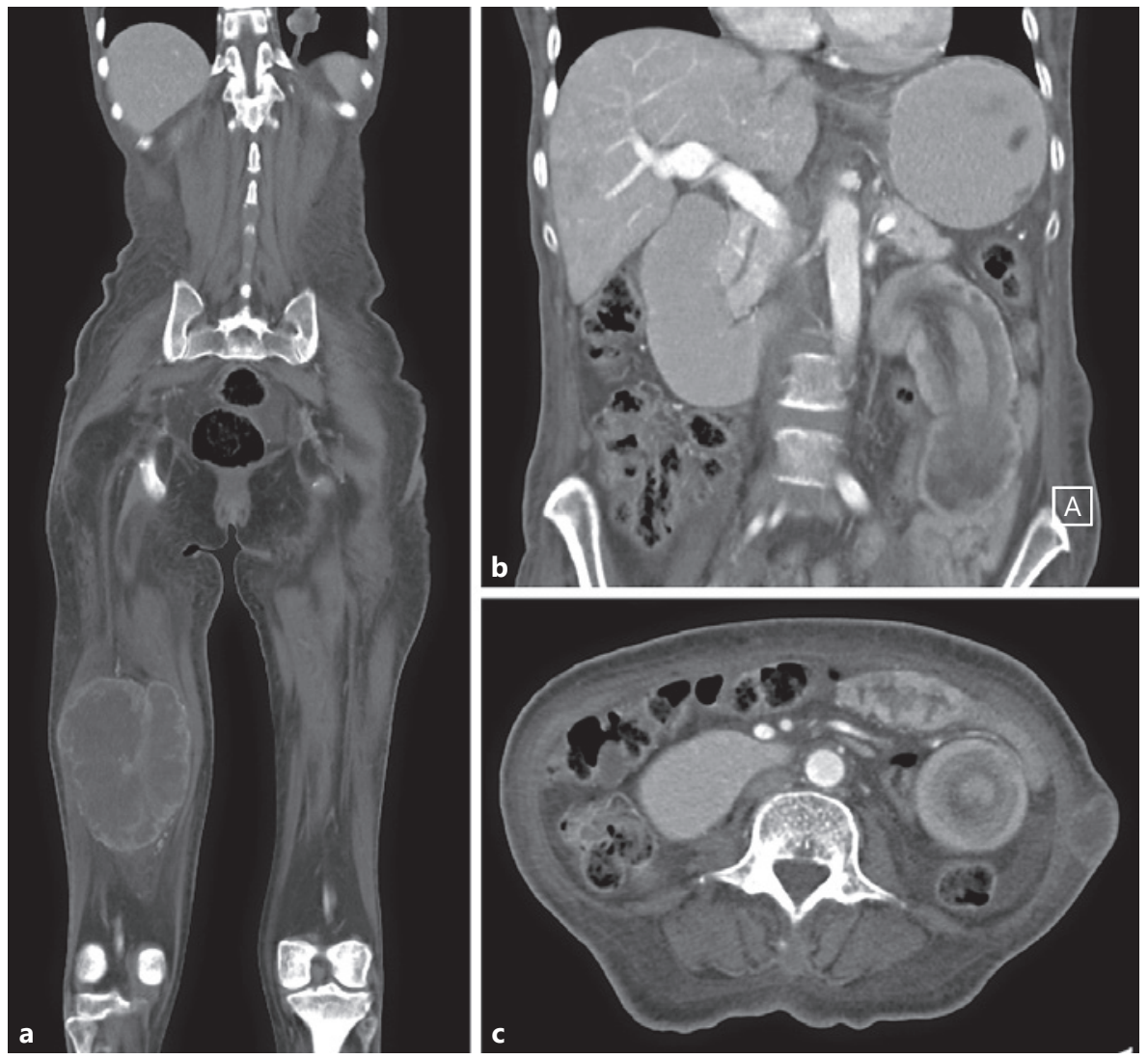

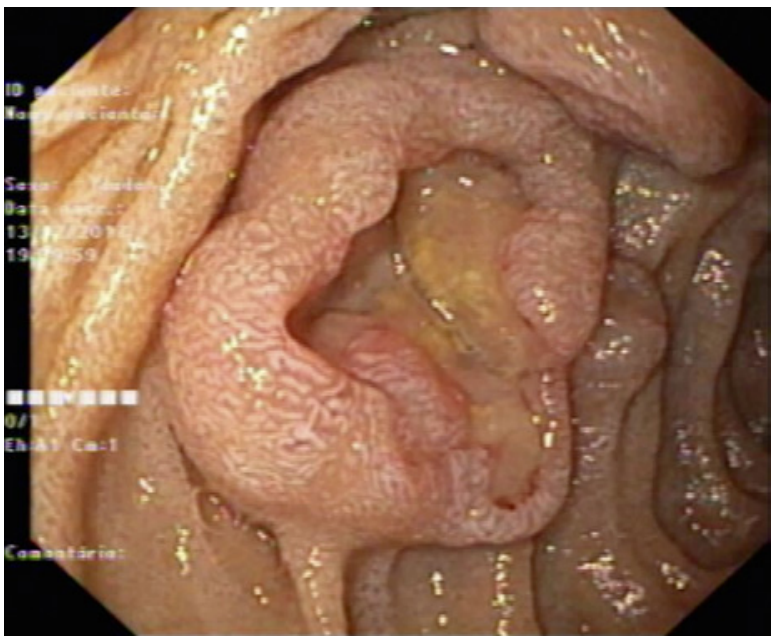

Fig. 2. Upper gastrointestinal endoscopy showing one of the duodenal lesions consistent with leiomyosarcoma.

ical history strongly suggests that the lower limb might have been the origin. Gastrointestinal bleeding and intestinal obstruction are the most common presenting signs of a small bowel leiomyosarcoma [1]. Surgical resection is the treatment of choice in patients with localized disease [2]. In the present case, multiple ulcerative lesions of the small bowel caused gastrointestinal bleeding and intestinal intussusception, leading to suboclusion. However, surgery was not considered since she had disseminated disease and bowel obstruction relieved with conservative measures. In fact, intussusception often reduces spontaneously, although it can recur [3]. Small bowel metastasis by leiomyosarcoma is usually a sign of extensive disease and carries an unfavorable prognosis. Data on chemotherapy for unresectable metastatic leiomyosarcoma are scarce [2]. The most commonly used drugs as initial treatment in metastatic soft tissue sarcomas - doxorubicin and ifosfamide - show limited efficacy for leiomyosarcoma, with response rates between 10 and $25 \%[1,2]$.

\section{Statement of Ethics}

The authors declare that this case did not require informed consent or approval by the ethics committee.

\section{Disclosure Statement}

The authors have no conflicts of interest to declare. 


\section{Funding Sources}

No funding was received for this work.

\section{References}

\section{Author Contributions}

Maria Pia Costa-Santos drafted the manuscript and reviewed the literature. João Moreira-Pinto, Maria Helena Oliveira, and Alexandre Oliveira Ferreira contributed with critical review of the manuscript and approval of the final version.
1 Hilal L, Barada K, Mukherji D, Temraz S, Shamseddine A. Gastrointestinal (GI) leiomyosarcoma (LMS) case series and review on diagnosis, management, and prognosis. Med Oncol. 2016 Feb;33(2):20.

2 Serrano C, George S. Leiomyosarcoma. Hematol Oncol Clin North Am. 2013 Oct;27(5): 957-74.
3 Guzel T, Mech K, Mazurkiewicz M, Dąbrowski B, Lech G, Chaber A, et al. A very rare case of a small bowel leiomyosarcoma leading to ileocaecal intussusception treated with a laparoscopic resection: a case report and a literature review. World J Surg Oncol. 2016 Feb;14(1):48. 